\title{
Desain Koper Pintar Untuk Business Traveller
}

\author{
Andesita Nurinda Wulandari, Agus Windharto \\ Departemen Desain Produk Industri, Fakultas Arsitektur, Desain dan Perencanaan, Institut Teknologi \\ Sepuluh Nopember (ITS) \\ e-mail: andesitanwsm@gmail.com
}

\begin{abstract}
Abstrak - Pariwisata merupakan sektor yang selalu berkembang di Indonesia. Hal ini dapat dilihat dari meningkatnya jumlah wisatawan Indonesia pada tahun 2014 sebesar 7.899.070 jiwa menjadi sebesar 7.908.534 pada tahun 2015. Perjalanan bisnis di Indonesia akan memiliki rata-rata dua kali lebih banyak dibandingkan tahun sebelumnya. Koper pintar merupakan salah satu jenis tas yang sedang marak diminati oleh traveller untuk membawa barang-barang bawaannya dengan jangka waktu perjalanan yang relatif lama. Menurut hasil survey yang telah dilakukan, para pelaku perjalanan bisnis atau biasa disebut business traveller, memiliki karateristik yang berbeda dengan traveller pada umumnya, seperti selalu membutuhkan daya listrik dimanapun mereka berada dan tingkat mobilitas yang sangat tinggi. Selain itu, kasus kehilangan koper dan penataan barang yang masih kurang baik juga merupakan salah satu permasalahan yang diangkat. Untuk mengatasi permasalahan tersebut, dibutuhkan suatu desain koper pintar yang dapat menyediakan sumber daya listrik, membantu mobilitas tinggi business traveller, mencegah kehilangan dan efektifitas dalam penyimpanan barang. Proses desain dimulai dengan mengumpulkan data literatur, observasi, shadowing, dan deep interview. Dari hasil pengumpulan data tersebut kemudian diolah kembali untuk mendapatkan suatu permasalahan dan kebutuhan, sehingga nantinya didapatkan sebuah solusi yang efektif sebelum memulai untuk melakukan analisis-analisis terkait. Dari hasil penelitian yang telah dilakukan, koper pintar ini diharapkan nantinya akan mampu untuk menyelesaikan masalah-masalah dan menjadi pilihan alternatif baru bagi para business traveller dalam menjalankan perjalanan bisnisnya.
\end{abstract}

Kata Kunci-Perjalanan bisnis, business traveller, koper pintar.

\section{PENDAHULUAN}

$\mathrm{P}$ ARIWISATA di Indonesia memiliki peningkatan hampir di setiap tahunnya. Menurut tabel yang disajikan di bawah, dapat dilihat bahwa pada tahun 2014, wisatawan nasional di Indonesia mencapai angka 7.899.070 jiwa, dan pada tahun berikutnya yaitu tahun 2015, jumlah wisatawan nasional meningkat menjadi 7.908.534 jiwa [1].

Salah satu bentuk travelling yang sedang hangathangatnya di Indonesia adalah perjalanan bisnis atau biasa disebut dengan business travelling. Menurut Visa Global Travel Intentions Study 2015, perjalanan bisnis di Indonesia akan meningkat rata-rata dua kali lebih banyak dibandingkan dengan perjalanan bisnis pada tahun-tahun sebelumnya [2]. Di Indonesia sendiri banyak faktor yang membuat orang-orang cenderung ingin melakukan perjalanan bisnis tersebut, salah satunya adalah kesempatan untuk mengunjungi daerah-daerah yang belum pernah dikunjungi sebelumnya. Perjalanan bisnis sendiri meliputi berbagai macam kegiatan dan durasi perjalanan yang berbagai macam. Banyaknya kegiatan dan macam-macam durasi perjalanan tersebut membuat business traveller memilih untuk menggunakan koper untuk perjalanan tersebut.

Istilah smart luggage memiliki arti yang berbeda beberapa tahun lalu, yaitu sebuah koper yang terlihat stylish dan juga elegant. Seiring berjalannya waktu, istilah tersebut memiliki arti yang berbeda. Pada jaman sekarang, smart luggage merupakan sebuah istilah bagi sebuah koper yang berhubungan dengan teknologi.

Permasalahan yang diangkat pada tugas akhir ini adalah:

1. Business traveller harus selalu terkoneksi dengan pekerjaannya, maka dari itu mereka harus selalu mendapatkan asupan daya listrik yang mudah dijangkau selama perjalanan bisnisnya.

2. Mobilitas yang sangat tinggi membuat business traveller harus mengeluarkan tenaga lebih untuk mencapai tempat yang dituju.

3. Kelalaian pengguna maupun maskapai penerbangan sering kali menyebabkan hilang / tertinggalnya koper di suatu tempat.

4. Padatnya kegiatan seorang business traveller dapat menimbulkan stress. Mereka jarang mendapatkan waktu untuk melakukan aktivitas yang menyenangkan di selasela sibuknya pekerjaan.

5. Masih kurang terorganisirnya antara barang bawaan penting seperti gadget, berkas-berkas pekerjaan, dengan barang-barang bawaan lainnya seperti baju, dan sebagainya.

\section{URAIAN PENELITIAN}

Dalam perancangan ini digunakan beberapa metode dan proses dalam mengumpulkan data-data yang diperlukan. Berikut adalah tahap-tahap dalam pengumpulan data dan proses desain:

\section{A. Tahap Pengambilan Data}

Metode pengambilan data diperoleh melalui pengumpulan literatur yang terkait dengan penelitian, shadowing, deep interview, dan story telling. Data primer didapat dengan melakukan shadowing untuk mengetahui apa saja kegiatan yang dilakukan oleh pengguna dengan kopernya, melakukan deep interview kepada beberapa pengguna, dan story telling dengan meminta kepada pengguna untuk menceritakan segala aktivitas dan apa saja yang dilakukan oleh pengguna selama 
menggunakan koper tersebut. Data sekunder didapat melalui studi literature internet dan jurnal terkait.

\section{B. Tahap Studi dan Analisis}

Tahapan studi dan analisis yang dilakukan dalam penelitian ini meliputi:

1. Studi analisis pasar: digunakan untuk mengetahui segmetasi, target pengguna, dan positioning produk pada pasar yang sudah ada.

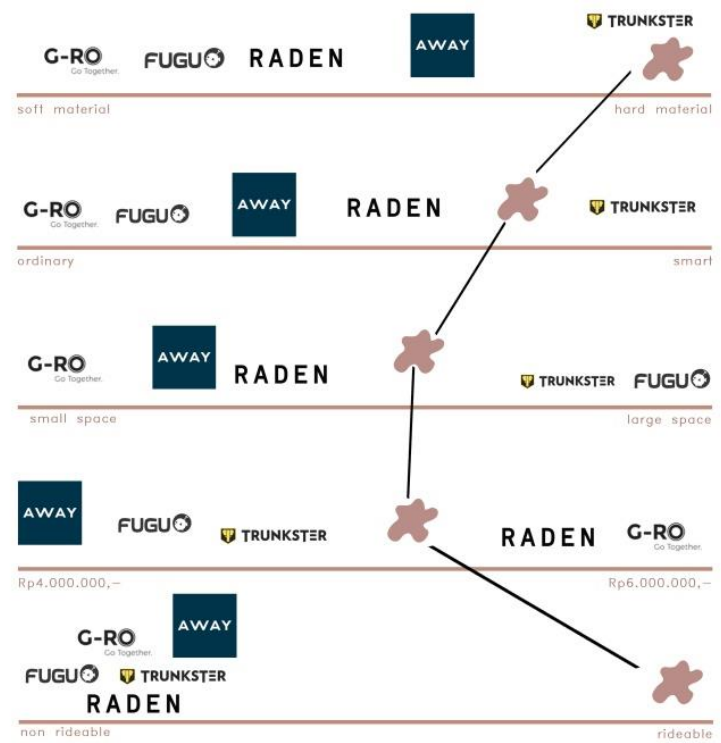

Gambar 1. Positioning produk.

2. Studi aktifitas dan barang bawaan: digunakan untuk mengetahui aktifitas-aktifitas apa saja yang dilakukan pengguna dan barang-barang apa saja yang dibawa selama menggunakan koper tersebut.

3. Studi analisis antropometri: untuk mengetahui acuan ukuran-ukuran dan titik kritis ergonomis koper.

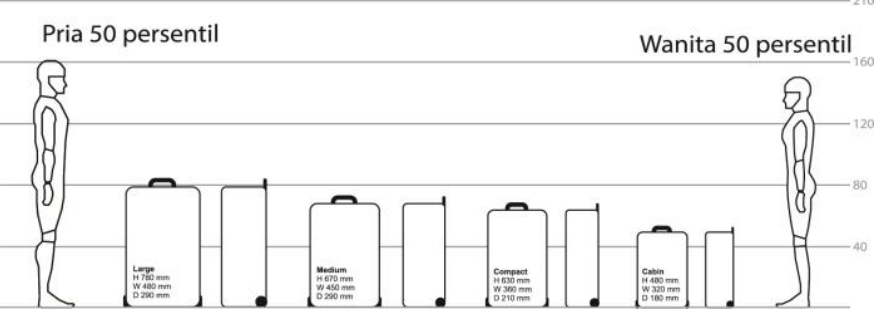

Gambar 2. Antropometri ukuran koper dan manusia.

4. Studi analisis part: untuk mengetahui part-part penting pada koper.

5. Studi analisis material: menentukan material terbaik apa yang dapat digunakan untuk koper yang akan di desain.

6. Analisis baterai: untuk mengetahui jenis baterai dan berapa tegangan yang dibutuhkan untuk fitur electric scooter.

7. Analisis layout baterai dan mesin: untuk mengetahui berapa jumlah dan rangkaian baterai dan juga mesin yang harus digunakan.
8. Analisis sistem wiring: mengidentifikasi cable wiring yang akan digunakan untuk fitur electric scooter.

9. Analisis cabin baggage allowance: untuk mengetahui berapa ukuran maksimal koper yang diperbolehkan untuk masuk ke dalam kabin pesawat dari berbagai maskapai di Indonesia.

10. Analisis tren \& style: untuk mengetahui warna dan style yang sedang tren dan cocok untuk diaplikasikan kepada desain.

11. Studi analis is pencarian konsep desain: untuk mengetahui bentuk dan konsep desain yang nantinya akan digunakan untuk koper tersebut.

\section{Tahap Pengembangan Desain}

1. Sketsa ide: pencarian ide awal dalam bentuk sketsa ide alternatif.

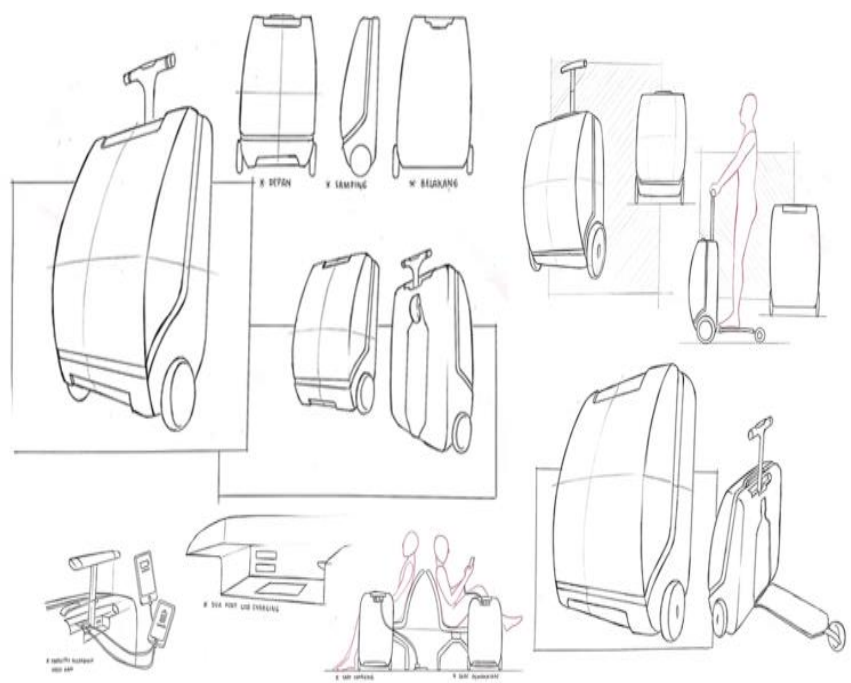

Gambar 3. Sketsa ide.

2. Studi model: digunakan untuk proses pencarian bentuk dengan ukuran yang sudah terskala.

3. Digital modelling: digunakan untuk menentukan detaildetail pada produk dan juga menemukan alternatifalternatif pada bagian-bagian produk.

4. Prototyping: desain yang sudah terpilih diwujudkan dalam bentuk prototip dengan skala 1:1 dan menggunakan material yang sebenarnya atau mendekati material as linya.

\section{HASIL PENELITIAN}

\section{A. Konsep Desain}

Konsep desain ditentukan berdasarkan permasalahan yang ada dan berdasarkan analisis-analis is yang telah dilakukan sebelumnya. Konsep-konsep yang didapatkan pada penelitian ini adalah sebagai berikut:

\section{1) Gadget Facility}

Yang dimaksud dengan gadget facility atau fasilitas gadget di sini adalah dimana business traveller yang menggunakan smart luggage ini tidak perlu takut untuk kehilangan daya gadget mereka saat berada di bandara. Smart luggage ini akan 
memberikan fitur untuk membantu pengguna mengisi daya baterai gadget mereka tanpa harus mencari charging station atau stop kontak saat berada di bandara.
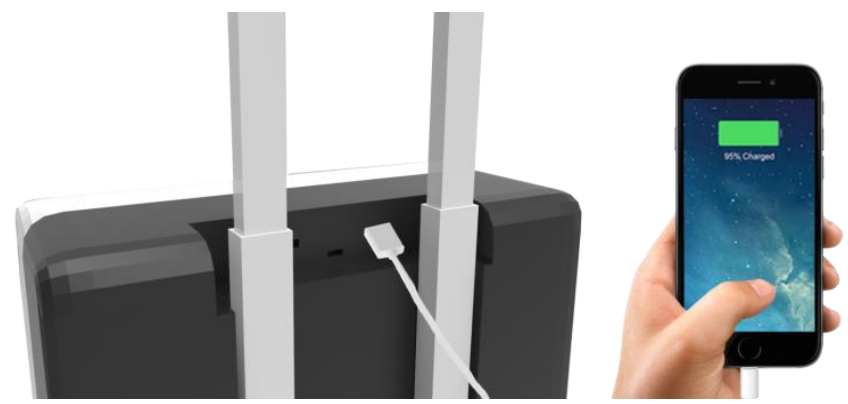

Gambar 4. Konsep gadget facility.

\section{2) Location Awareness}

Konsep location awareness ini untuk membantu para pengguna smart luggage ini agar selalu waspada dan selalu tahu dimana keberadaan koper mereka melalui gadget / smartphone mereka dengan GPS tracker. Hal ini untuk meminimalisir kasus kehilangan koper.
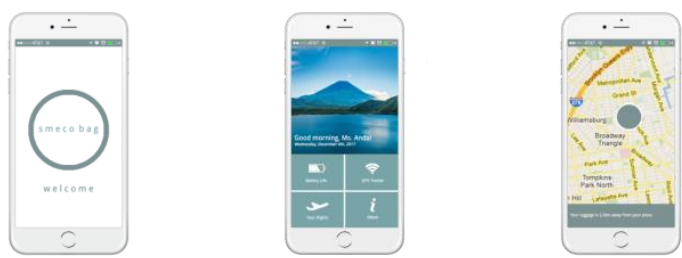

Gambar 5. User interface GPS tracker.

\section{3) Carry the User}

Konsep ini merupakan sebuah konsep dimana smart luggage ini tidak hanya dapat membawa barang-barang bawaan pengguna, namun smart luggage ini juga dapat membawa penggunanya dengan fitur electric scooter untuk menunjang mobilitas tinggi pengguna tersebut. Dengan fitur electric scooter tersebut diharapkan pengguna dapat menuju tempat tujuan lebih cepat dan diharapkan dapat memberikan hiburan tersendiri bagi pengguna di sela-sela kesibukannya.

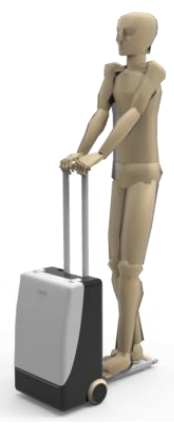

Gambar 6. Konsep carry the user dengan electric scooter.

\section{4) Well-Organized}

Konsep ini merupakan konsep agar barang-barang bawaan pengguna terutama barang-barang penting seperti gadget, dan berkas-berkas keperluan perjalanan bisnisnya dapat terorganisir dengan baik. Smart luggage ini memberikan sebuah tas tambahan untuk barang-barang penting pengguna ya dapat langsung dikeluarkan dan dibawa sendiri tanpa harus membawa smart luggage-nya.
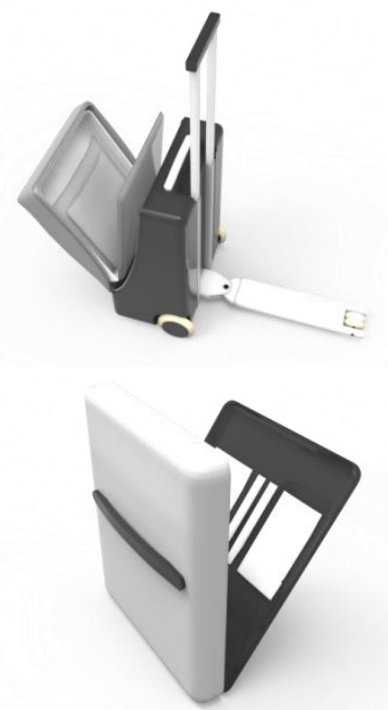

Gambar 7. Konsep well-organized.

\section{B. Prototyping}

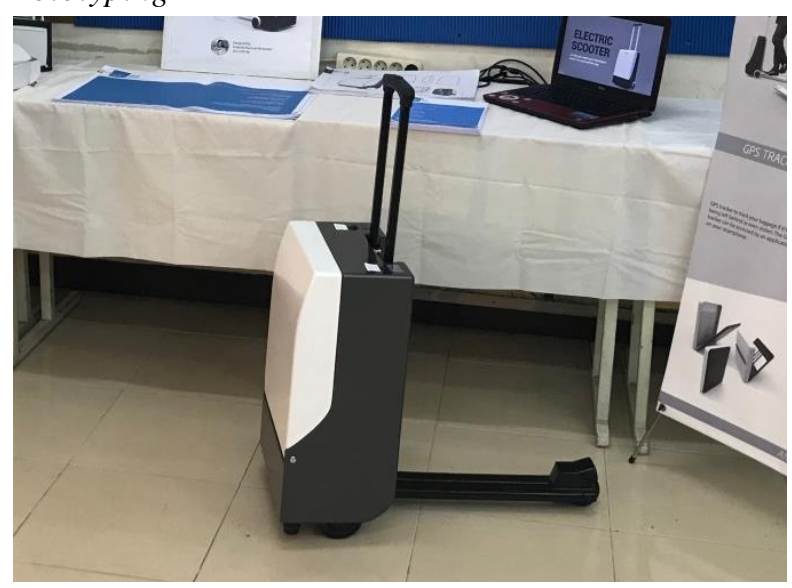




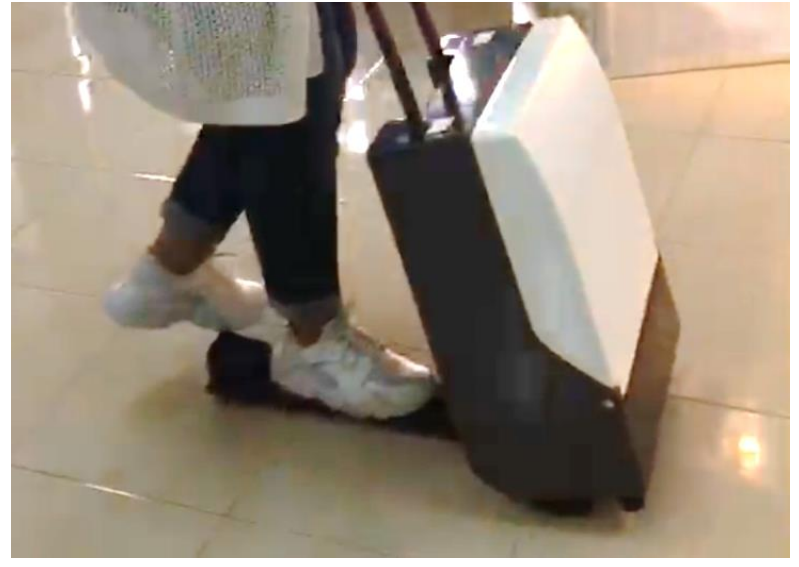

Gambar 8. Protoyping koper.

Pembuatan prototip dilakukan dengan mitra kerja penulis dalam waktu 1 bulan. Prototip menggunakan material kayu triplek untuk body koper dan alumunium untuk bagian scooter. Setelah selesai, dilakukan pula uji coba pada electric scooter. Dari prototip ini, penulis dapat menyimpulkan beberapa kesimpulan dan juga mendapat beberapa masukan berupa saran-saran untuk memperbaiki desain.

\section{KESIMPULAN}

\section{A. Kesimpulan}

Berdasarkan hasil akhir penelitian yang ditujukan untuk menjawab permasalahan-permasalahan kebutuhan business traveller yang menggunakan koper saat melakukan perjalanan bisnis, dapat ditarik beberapa kesimpulan, yaitu:

1. Dari desain yang telah dibuat, dapat menyelesaikan permasalahan pengguna yang selalu merasa kesusahan mencari charging station atau stop kontak yang tersedia ketika di bandara. Pengguna tidak perlu bersusah-susah untuk mencari sumber daya listrik, pengguna hanya perlu menyambungkan kabel USB charge milik mereka pada lubang USB yang sudah disediakan pada smart luggage tersebut.

2. Sumber listrik built-in charge yang ada pada smart luggage tidak perlu menggunakan sebuah power bank tambahan, melainkan dapat mengambil langsung dari sumber baterai electric scooter yang ada sehingga dapat menghemat ruang yang tersedia untuk barang bawaan.

3. Fitur electric scooter yang dapat berjalan dengan kecepatan maksimal $10 \mathrm{~km} / \mathrm{h}$ ini dapat membawa pengguna ke tujuan yang dituju lebih cepat dibandingkan dengan berjalan. Selain itu pengguna dapat menghemat waktu.

\section{B. Saran}

Pada pengembangan desain smart luggage selanjutnya dianjurkan untuk:

1. Menggunakan jenis mesin DC yang berukuran lebih kecil, sehingga ruang untuk barang bawaan pengguna dapat lebih luas dan dapat meminimalisir berat smart luggage itu sendiri.

2. Memperlebar handle trolley agar dapat memberikan keringanan bagi pengguna saat mengarahkan / membelokkan scooter.

3. Menggunakan metode vacuum / resin dalam membuat prototoype.

4. Memperbaiki struktur utama electric scooter agar dapat memberikan kesan yang lebih kokoh dan juga durable.

\section{DAFTAR PUSTAKA}

[1] Kementerian Pariwisata Indonesia, "Kementerian Pariwisata Indonesia." [Online]. Available: http://www.kemenpar.go.id/asp/detil.asp?c=112\&id=1358.

[2] Anonimus, "orang indonesia lakukan lebih banyak perjalanan bisnis dibanding pebisnis global," www.beritasatu.com. 